\title{
Characterization of a malaria outbreak in Colombia in 2010
}

Pablo Chaparro ${ }^{1,2^{*}}$, Julio Padilla ${ }^{3}$, Andrés F Vallejo ${ }^{4,5}$ and Sócrates Herrera ${ }^{4,5}$

\begin{abstract}
Background: Although malaria has presented a significant reduction in morbidity and mortality worldwide during the last decade, it remains a serious global public health problem. In Colombia, during this period, many factors have contributed to sustained disease transmission, with significant fluctuations in an overall downward trend in the number of reported malaria cases. Despite its epidemiological importance, few studies have used surveillance data to describe the malaria situation in Colombia. This study aims to describe the characteristics of malaria cases reported during 2010 to the Public Health Surveillance System (SIVIGILA) of the National Institute of Health (INS) of Colombia.

Methods: A descriptive study was conducted using malaria information from SIVIGILA 2010. Cases, frequencies, proportions, ratio and measures of central tendency and data dispersion were calculated. In addition, the annual parasite index (API) and the differences between the variables reported in 2009 and 2010 were estimated.

Results: A total of 117,108 cases were recorded by SIVIGILA in 2010 for a national API of 10.5/1,000 habitants, with a greater number of cases occurring during the first half of the year. More than $90 \%$ of cases were reported in seven departments (=states): Antioquia: 46,476 (39.7\%); Chocó: 22,493 (19.2\%); Cordoba: 20,182 (17.2\%); Valle: 6,360 (5.4\%); Guaviare: 5,876 (5.0\%); Nariño: 4,085 (3.5\%); and Bolivar: 3,590 (3.1\%). Plasmodium vivax represented 71\% of the cases; Plasmodium falciparum 28\%; and few infrequent cases caused by Plasmodium malariae.
\end{abstract}

Conclusions: Overall, a greater incidence was found in men (65\%) than in women (35\%). Although about a third of cases occurred in children $<15$ years, most of these cases occurred in children $>5$ years of age. The ethnic distribution indicated that about $68 \%$ of the cases occurred in mestizos and whites, followed by $23 \%$ in Afrodescendants, and the remainder (9\%) in indigenous communities. In over half of the cases, consultation occurred early, with 623 complicated and 23 fatal cases. However, the overall incidence increased, corresponding to an epidemic burst and indicating the need to strengthen prevention and control activities as well as surveillance to reduce the risk of outbreaks and the consequent economic and social impact.

Keywords: Colombia, Malaria surveillance, Epidemiology, Plasmodium vivax, Plasmodium falciparum

\section{Background}

Malaria is caused by one or more of the five species of Plasmodium that can infect humans (Plasmodium vivax, Plasmodium falciparum, Plasmodium malariae, Plasmodium ovale, Plasmodium knowlesi) after transmission by the bite of malarial female Anopheles mosquitoes. Although $P$. falciparum is highly prevalent worldwide, $P$. vivax has a wider distribution [1] and is the prevalent species outside the African continent. Plasmodium ovale and

\footnotetext{
* Correspondence: pchaparro@ins.gov.co

'National Institute of Health of Colombia, Bogotá, Colombia

${ }^{2}$ National University of Colombia, Bogotá, Colombia

Full list of author information is available at the end of the article
}

P. malariae are mainly transmitted in tropical areas of Africa and some islands of Southeast Asia [2], whereas P. knowlesi seems to be restricted to Southeast Asia [3]. Between 2005 and 2009, the estimated global number of malaria cases decreased from 237 million to 222 million, while the estimated number of malaria deaths during the same period decreased from $>800,000$ cases in 2005 to 691,000 cases in $2009(\sim 14 \%)$ [4].

In the American continent, malaria affects 23 countries, where about $20 \%$ of the population is at some risk of disease [5]. Brazil and Colombia are the major contributors of malaria cases in the region, accounting for $67 \%$ of the

\section{Biomed Central}

(c) 2013 Chaparro et al.; licensee BioMed Central Ltd. This is an Open Access article distributed under the terms of the Creative Commons Attribution License (http://creativecommons.org/licenses/by/2.0), which permits unrestricted use, distribution, and reproduction in any medium, provided the original work is properly cited. 
total malaria cases, followed by Haiti, Peru and Venezuela. Altogether the five countries accounted for $91 \%$ of the cases reported in the American continent in 2009 [5,6]. In general, $P$. vivax is responsible for most of the malaria cases of the continent (70\%), which have been estimated to range between 1.9 million in 2005 and 1.1 million in 2009 .

During the last decade several countries of the continent have presented a significant and stable decrease in malaria incidence: Peru and Ecuador in South America; and Guatemala, Honduras, El Salvador, Costa Rica, and Panama in Central America (decreased by $>60 \%$ malaria transmission). However, in Colombia, during the same period, morbidity has remained high, with malaria cases fluctuating between 231,000 and 66,000 cases per year [5].

About $85 \%$ of the Colombian rural territory is at an altitude less than 1,600 $\mathrm{m}$ above sea level, and thus presents climatic, geographic and epidemiological conditions suitable for malaria transmission. It is estimated that approximately a quarter $(\sim 11$ million people) of its current national population, estimated at 45 million people, live permanently at risk of infection [7]. This portion of the national population reside in areas where environmental factors such as temperature, humidity, precipitation, latitude and altitude, as well as social, cultural, economic and political factors compromise the effectiveness of prevention and control programs. Despite the relatively higher rate of malaria transmission in Colombia, it is still considered unstable with endemic-epidemic patterns and focal variables in different eco-epidemiological regions [8].

In general, during the last seven years, the Colombian National Malaria Control Programme (NMCP) has targeted its activities on reducing the interaction among vectors, parasites and human hosts through strategies such as case management, prevention and surveillance $[9,10]$. Malaria case management is focused on early detection, i.e., diagnosis of malaria cases and prompt and effective treatment of symptomatic patients. This is based on an extended diagnostic network with >1,700 laboratories and 1,195 microscopists where most cases are detected by passive surveillance using thick blood smears (TBS), although there is a growing use of rapid diagnostic tests (RDT) [11]. Treatment is based on the use of artemether/lumefantrine for $P$. falciparum and chloroquine + primaquine for $P$. vivax, according to the respective parasite sensitivity to these anti-malarials. Prevention activities cover a wide variety of strategies, ranging from preventive health education to vector control measures, including the use of insecticide-impregnated nets (ITNs) and in-door residual spraying (IRS) with longlasting insecticides, particularly DDT, deltametrin and lambda-cyhalotrin. Monitoring includes passive case detection performed by a network of community collaborators that contribute with diagnosis, monitoring and evaluation of the NMCP, whereas active detection of malaria cases is only performed during epidemic outbreaks $[9,10]$.
Besides the usual activities of the NMCP, a project sponsored by the Global Fund (GF) for AIDS, tuberculosis and malaria between 2005 and 2010 was directed at reducing malaria transmission at adjacent country borders (PAMAFRO) that included Peru, Ecuador, Colombia, and Venezuela. This project significantly contributed to a decline in malaria transmission, particularly in bordering departments such as Nariño in the south-western region of Colombia. Moreover, since 2010, a new five-year GF project is being conducted in the five departments (=states) that contribute $>80 \%$ of malaria cases in Colombia: Cordoba, Antioquia, Chocó, Valle del Cauca, and Cauca. The strategy of this ongoing GF project is to train community workers who will be responsible for leading disease prevention processes: organization of surveillance committees, ensuring notification and promoting access to RDT-based diagnosis and immediate treatment.

In spite of the significant national efforts against malaria, the impact of all these activities has been hampered by situations such as armed conflicts, illegal agriculture and mining, social inequality, climate change, and the rather cumbersome administrative structure of the NMCP [12]. The latter includes decentralization of the NMCP, which has been attempting to transfer control activities to the social security system (SSS) since 2000. The SSS is composed of health provider enterprises (EPS) and health provider institutions (IPS) with relatively low malaria technical and operational capacity in some departments and municipalities, together with a general lack of political will and social responsibility.

Because of the paucity of reports that describe the current national malaria situation, the aim of this study was to describe the characteristics of malaria cases reported in Colombia during 2010 as a starting point for prioritizing a prevention and control agenda.

\section{Methods}

\section{Study design and case definitions}

A descriptive study was conducted using data from SIVIGILA 2010. Definitions established by this surveillance system were adopted for laboratory-confirmed uncomplicated malaria cases, probable cases, and severe and complicated malaria [8], as described in Table 1.

\section{Descriptive variables}

Variables considered in the descriptive analysis were: parasite species, number of uncomplicated malaria and lethal cases during the year, department and municipality of origin, duration (months) of consultation, age, gender, type of health regime, and ethnicity. Additionally, "time between symptoms and consultation" was included as a variable corresponding to the time between the symptoms onset and the date of consultation. 
Table 1 Definitions used in this study*

\begin{tabular}{|c|c|}
\hline Complication & Description \\
\hline Cerebral malaria & $\begin{array}{l}\text { Altered state of consciousness (irreversible coma), unconsciousness with the possibility of waking up, prostration, } \\
\text { extreme weakness (patient cannot sit or stand), generalized convulsions or behavioral disturbance. }\end{array}$ \\
\hline Renal complication & $\begin{array}{l}\text { Serum creatinine }>3.0 \mathrm{mg} / \mathrm{dl} \text { and/or urine vol }<400 \mathrm{ml} \text { in } 24 \text { hours (adults) or }<12 \mathrm{ml} / \mathrm{kg} \text { of body weight in } \\
24 \text { hours (children) }\end{array}$ \\
\hline $\begin{array}{l}\text { Lung or respiratory distress } \\
\text { syndrome }\end{array}$ & $\begin{array}{l}\text { Increased respiratory rate at admission, presence of abnormal lung sounds, such as wheezing, rhonchi, rales, and } \\
\text { radiographic changes consistent with pulmonary oedema. }\end{array}$ \\
\hline Shock & Systolic blood pressure $<70 \mathrm{~mm} \mathrm{Hg}$ in adults or $<50 \mathrm{~mm} \mathrm{Hg}$ in children. \\
\hline Hypoglycaemia & Glucose $<40$ mg/dl. \\
\hline Hyperemesis & Uncontrollable and frequent vomiting, $>5$ times in 24 hours, which prevents anti-malarial treatment orally. \\
\hline Hyperpyrexia & Axillary temperature $>39.5^{\circ} \mathrm{C}$ \\
\hline Severe anemia & $\begin{array}{l}\text { Haematocrit }<15 \% \text { or } \mathrm{Hb}<5 \mathrm{~g} / \mathrm{dl} \text {, Spontaneous bleeding or disseminated intravascular coagulation (DIC), } \\
\text { acidaemia/acidosis (clinical signs), macroscopic haemoglobinuria }\end{array}$ \\
\hline Complicated malaria case & $\begin{array}{l}\text { Any patient with probable case of malaria complicated by the presence of asexual (trophozoites/schizonts) of } P \text {. } \\
\text { falciparum confirmed by parasitological examination and who has been ruled out another etiology, or any patient } \\
\text { with confirmed cases of malaria with }>50,000 \text { parasite asexual forms } / \mu \mathrm{L} \text { (hyperparasitaemia) }\end{array}$ \\
\hline Death from malaria & $\begin{array}{l}\text { Patient with signs and symptoms of complicated malaria, with confirmed diagnose of } P \text {. falciparum (or } P \text {. vivax) or } \\
\text { associated infection. }\end{array}$ \\
\hline Complication hepatic jaundice & Total serum bilirubin $>3 \mathrm{mg} / \mathrm{dl}$ and altered liver function tests. \\
\hline
\end{tabular}

* SIVIGILA definitions.

\section{Database mining}

Databases were refined taking into account the recommendations of the monitoring system. In general, these recommendations address validation rules that take into account the variable code, date of service, epidemiological week, type identification, identification number, primary data generating units (PDGU) and information units (IU), which emphasize the assessment of repeated and duplicate cases [13].

\section{Statistical methods}

Information was processed using spreadsheets and Microsoft Excel for analysis, using Tableau statistical package, version 6.0. Univariate analyses were performed for all variables included. The proportions, vivax/falciparum ratio, and measures of central tendency and dispersion were calculated. The API was calculated by relating the total number of malaria cases $(117,108)$ in 2010 with the population at mid-term risk for the same year (10.2 million), multiplied by a thousand. The chi-square test was used to assess differences between the variables reported in 2010 compared with the previous year, and to calculate P values; which was considered statistically significant when $<0.05$.

\section{Results}

A total of 117,108 diagnosed malaria cases were recorded during 2010 by SIVIGILA; 77,586 of which, equivalent to $66.3 \%$ of all cases for the year, were reported during the first half of the year. These numbers corresponded to a $32.6 \%$ increase from the 78,498 cases reported in 2009 ( $<<0.001$ ), which constituted an epidemic year (Figure 1).
Twenty percent (7/32) of the Colombian departments, represented by the departments of Antioquia, Cordoba, Chocó, Guaviare, Vichada, Valle del Cauca and Amazon, presented an IPA above the national average of 10.5 cases/ 1,000 habitants (Figure 2). Additionally, stratification by territorial entity (departments and districts) according to the IPA indicated that in these seven states, $27.7 \%$ of the rural population presented $87.9 \%$ of cases, leading to an IPA $>10 / 1,000$, and representing areas of high malaria transmission risk. As shown in Table 2, most cases were reported in Antioquia (39.7\%), followed by Chocó (19.2\%), Córdoba (17.2\%), Valle (5.4\%), Guaviare (5.0\%), Nariño (3.5\%), and Bolivar (3.1\%) cases. Another 14 departments accounting for $33.2 \%$ of the rural population recorded $11.0 \%$ of cases and, therefore, displayed an IPA between 1-9 11,000 , and were classified as medium-risk regions. In the remaining 15 entities, with $39.1 \%$ of the rural population, reported only $0.9 \%$ of the cases, presented an IPA $<1.0 /$ 1,000, and were, therefore, considered of low risk. Table 2 shows the specific increase in the number of malaria cases observed in the period 2009-2010 by territorial entity. Despite the fact that not all of the territorial entities reported an increase in malaria, five of the most endemic (Antioquia, Chocó, Cordoba, Guaviare and Valle) reported an average increase of $44 \%$.

Most cases were caused by only one parasite species. Plasmodium vivax was identified in 82,856 (70.8\%) cases, $P$. falciparum in 32,777 (28.0\%) cases, and P. malariae in 47 $(0.04 \%)$ cases. Additionally, 1,428 cases of mixed infections (P. falciparum and P. vivax, $1.2 \%$ ) were reported. The ratio of $P$. vivax to $P$. falciparum cases was 2.5 to 1 . Most of the territorial entities had a higher proportion of $P$. vivax, 


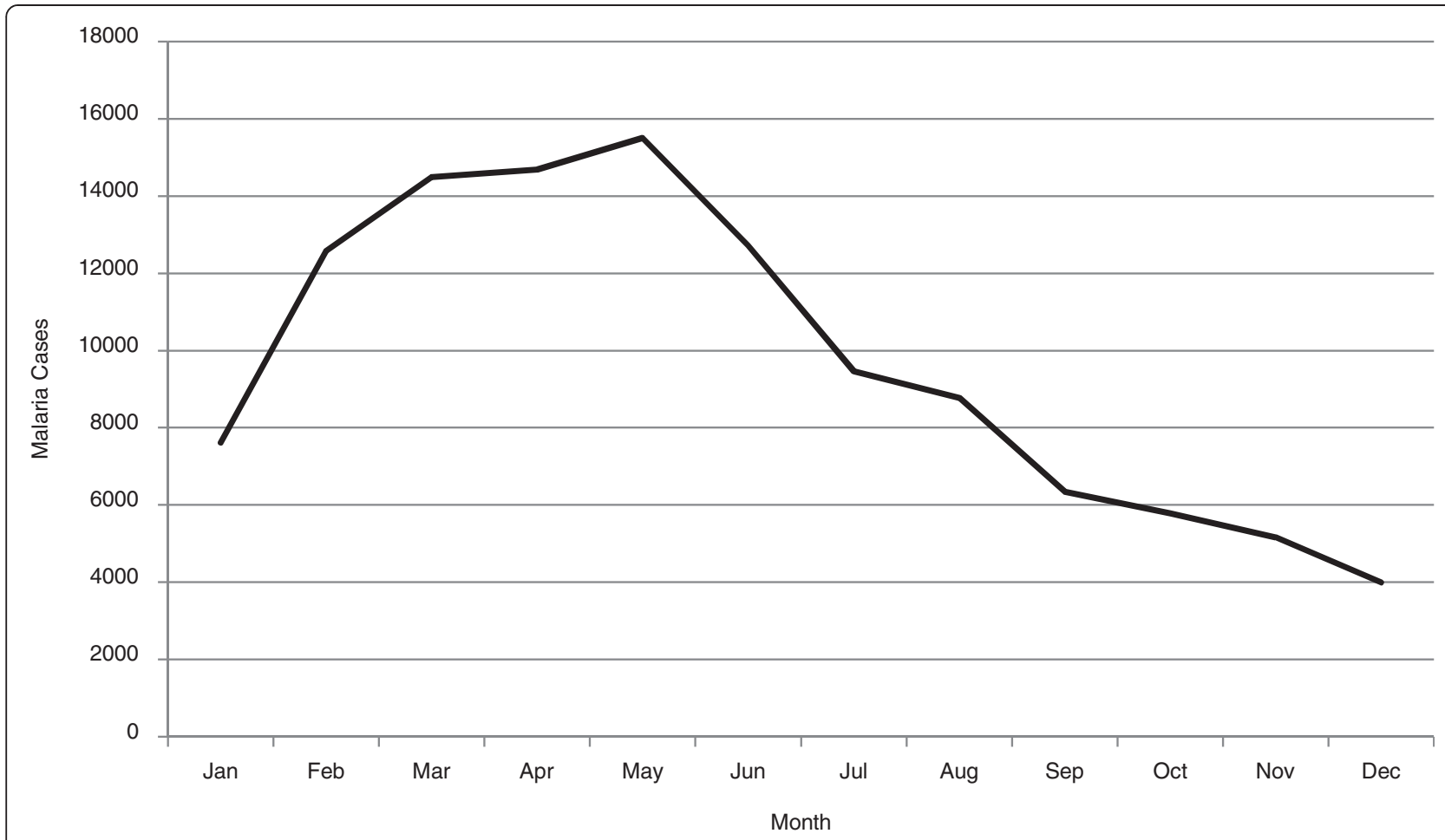

Figure 1 Distribution of malaria cases by month, Colombia, 2010.

except in Nariño, where $P$. falciparum was the predominant species ( $P$. vivax/ P. falciparum $=1: 5$ ) (Figure 3). Likewise, most cases $(75,636=64.6 \%)$ occurred in men and $41,472=35.4 \%$ in women. Age ranged from the first day of life to 101 years (median age, 22 years). The IPA distribution by sex and age was higher for men, with similar distribution for all age groups (Figure 4). The higher API values converged on the group of 20 to 24 years: $72.9 \%$ in men and $27.1 \%$ women.

Of people affected by malaria, 73,805 (63.0\%) were from rural areas; 24,779 (21.2\%) from small villages and 18,508 (15.8\%) from municipalities. Regarding the social security system, nearly two-thirds of the participants were enrolled $(68,029,58.1 \%)$, while 49,070 (41.9\%) cases were not. The ethnic group analysis showed that 27,382 (23.4\%) occurred in groups of African descent; 9,311 (8.0\%) in Native Americans; 299 (0.3\%) in raizales; 98 (0.1\%) in Gypsy; 22 (0.02\%) in palenqueros; and 79,988 $(68.3 \%)$ in white/mestizo population. In terms of occupation, $75.4 \%$ of the reported cases were categorized as follows: 29,294 (25.0\%) students; 16,769 (14.3\%) miners; 15,072 (12.9\%) housewives; 10,264 (8.8\%) children; 8,077 (6.9\%) farmers; 5,329 (4.6\%) soldiers; 3,494 (3.0\%) forest workers. In relation to the time between the symptoms onset and the time of diagnosis, there was a median of two days (range: 0-309). 54.2\% of the cases consulted within 48 hours after symptoms onset (Table 3 ). Eight departments had clinical care percentages that exceeded the national average, including Antioquia and Cordoba, which qualified as high risk according to the API with 57.0 and $64.5 \%$, respectively.

\section{Malaria in children under 15 years of age}

Of the 117,108 cases reported in $2010,35,458$ (30.3\%) occurred in children under 15 years; 840 (2.4\%) were aged under one year; 11,917 (33.6\%) belonged to the group of one to four years; $9,838(27.7 \%)$ were in the group of five to nine years; and $12,863(36.3 \%)$ were in the ten to 14 year-age group. Parasite species distribution in this group was 26,142 (73.7\%) with $P$. vivax and 8,998 (25.4\%) with $P$. falciparum. The proportion of $P$. vivax cases in the group $\leq 15$ years was 1.25 times higher than in $\geq 15$ (95\% $\mathrm{CI}=1.21-1.29, \mathrm{p}=0.000)$. Malaria cases in children $<15$ years were concentrated in three territorial entities, 67,292 (82.5\%) with an API $\geq 10$ : Antioquia: 12,204 (34.4\%); Chocó: 9,033 (25.5\%); Cordoba: 8,030 (22.6\%). About half of the cases $(54.7 \%)$ in this age group consulted within the first 48 hours after symptom onset.

\section{Malaria during pregnancy}

A total of 29,345 malaria cases occurred in women of reproductive age (ten to 54 years); 251 (0.9\%) of which were pregnant, with $>70 \%$ of gestational malaria cases concentrated in a few departments. Antioquia reported $45.8 \%$ of the cases $(115 / 251 ; \mathrm{p}=0.016)$; followed by Córdoba: $11.6 \% \quad(29 / 251 ; \quad p=0.005) ; \quad$ Choco: $8.4 \%$ 


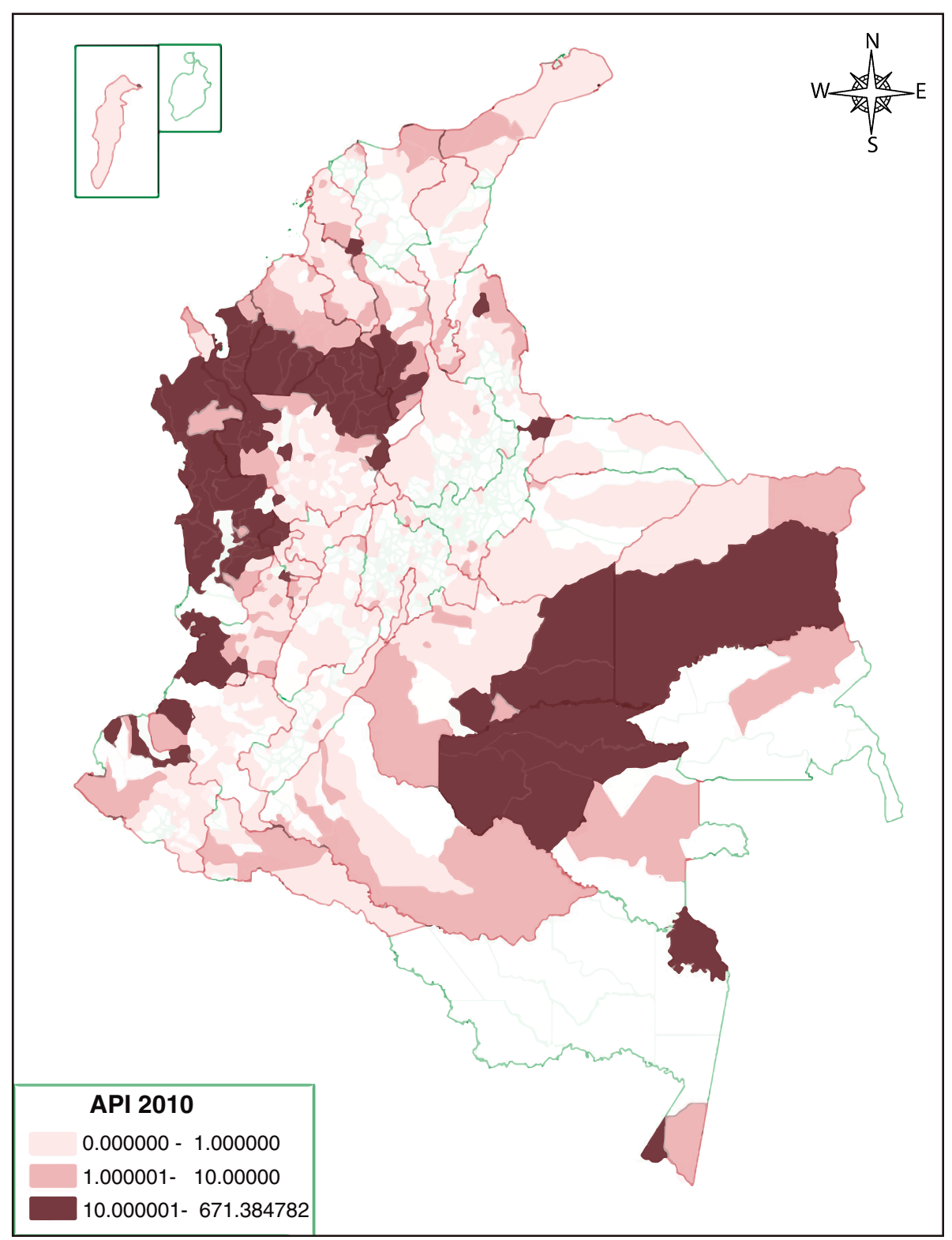

Figure 2 Annual parasite index by territorial entity.

$(21 / 251 ; \mathrm{p}=0.01)$; Guaviare: $7.6 \% \quad(19 / 251 ; \mathrm{p}=0.011)$. Almost half of the cases $(45.8 \%)$ consulted within the first 48 hours after symptom onset and no significant difference was observed in the parasite species presented by pregnant and non-pregnant women.

\section{Complicated malaria}

A total of $623(0.5 \%)$ complicated malaria cases were reported, caused almost equally by $P$. vivax and $P$. falciparum with most patients $(70.1 \%)$ in the age group of 15 to 64 years, and the remainder $(27.9 \%)$ occurred in children $<15$ years old. Liver failure (39.2\%) and renal failure
(26.8\%) were the most frequently reported complications (Table 4).

\section{Deaths from malaria}

Twenty-three $(0.02 \%)$ deaths attributable to malaria were produced in equal proportion by $P$. vivax (47.8\%) and $P$. falciparum (47.8\%), with most cases $(69.6 \%)$ occurring in patients aged 0 to 29 years, although the range varied between ten months to 80 years old (median age, 27 years) These deaths occurred in 15 (65.2\%) women and $8(34.8 \%)$ men. The most frequent complications were brain (47.8\%) and lung (30.4\%) diseases, and surprisingly, $43.5 \%$ of the cases were recorded as having 
Table 2 Distribution of malaria cases by parasite species and department (=state)

\begin{tabular}{|c|c|c|c|c|c|c|c|c|c|}
\hline \multirow[t]{3}{*}{ Territorial entity } & \multicolumn{4}{|c|}{2009} & \multicolumn{4}{|c|}{2009} & \multirow{3}{*}{$\begin{array}{c}\begin{array}{c}\text { Rate of } \\
\text { change }\end{array} \\
\%\end{array}$} \\
\hline & \multicolumn{2}{|c|}{$P$. vivax } & \multicolumn{2}{|c|}{ P. falciparum } & \multicolumn{2}{|c|}{$P$. vivax } & \multicolumn{2}{|c|}{ P. falciparum } & \\
\hline & $\mathrm{n}$ & $\%$ & $\mathrm{n}$ & $\%$ & $\mathrm{n}$ & $\%$ & $n$ & $\%$ & \\
\hline Antioquia & 26.341 & 33,42 & 6.059 & 7,69 & 36.620 & 31,27 & 9.463 & 8,08 & 29,7 \\
\hline Córdoba & 10.248 & 13 & 3.008 & 3,82 & 14.281 & 12,19 & 5.696 & 4,86 & 33,6 \\
\hline Chocó & 5.180 & 6,57 & 2.931 & 3,72 & 12.543 & 10,71 & 9.608 & 8,2 & 63,4 \\
\hline Guaviare & 1.065 & 4,3 & 1.184 & 1,5 & 4.940 & 4,22 & 877 & 0,75 & 21,4 \\
\hline Nariño & 3.388 & 1,35 & 4.505 & 5,72 & 693 & 0,59 & 3.381 & 2,89 & $-36,7$ \\
\hline Valle del Cauca & 991 & 1,26 & 913 & 1,16 & 5.061 & 4,32 & 1.213 & 1,04 & 69,7 \\
\hline Meta & 1.427 & 1,81 & 265 & 0,34 & 1.069 & 0,91 & 372 & 0,32 & $-17,4$ \\
\hline Cauca & 149 & 0,19 & 1.730 & 2,19 & 151 & 0,13 & 708 & 0,6 & $-118,7$ \\
\hline Amazonas & 1.729 & 2,19 & 82 & 0,1 & 747 & 0,64 & 33 & 0,03 & $-132,2$ \\
\hline Vichada & 1.226 & 1,56 & 246 & 0,31 & 535 & 0,46 & 269 & 0,23 & $-83,1$ \\
\hline Risaralda & 1.010 & 1,28 & 29 & 0,04 & 1.053 & 0,9 & 139 & 0,12 & 12,8 \\
\hline Bolívar & 849 & 1,08 & 65 & 0,08 & 2,6 & 2,22 & 755 & 0,64 & $-20,6$ \\
\hline La Guajira & 955 & 1,21 & 24 & 0,03 & 315 & 0,27 & 42 & 0,04 & $-174,2$ \\
\hline Putumayo & 721 & 0,91 & 6 & 0,01 & 236 & 0,2 & 11 & 0,01 & $-194,3$ \\
\hline Norte Santander & 237 & 0,3 & 1 & 0 & 346 & 0,3 & 2 & 0 & 31,6 \\
\hline Caquetá & 169 & 0,21 & 44 & 0,06 & 220 & 0,19 & 33 & 0,03 & 15,8 \\
\hline Sucre & 182 & 0,23 & 27 & 0,03 & 177 & 0,15 & 23 & 0,02 & $-4,5$ \\
\hline Vaupés & 100 & 0,13 & 24 & 0,03 & 205 & 0,18 & 4 & 0 & 40,7 \\
\hline Caldas & 26 & 0,03 & 28 & 0,04 & 201 & 0,17 & 21 & 0,02 & 75,7 \\
\hline Magdalena & 104 & 0,13 & 61 & 0,08 & 35 & 0,03 & 7 & 0,01 & $-292,9$ \\
\hline Guainía & 105 & 0,13 & 14 & 0,02 & 72 & 0,06 & 4 & 0 & $-56,6$ \\
\hline Quindío & 76 & 0,1 & 11 & 0,01 & 83 & 0,07 & 22 & 0,02 & 17,1 \\
\hline Boyacá & 62 & 0,08 & 4 & 0,01 & 118 & 0,1 & 5 & 0 & 46,3 \\
\hline Outside & 102 & 0,13 & 7 & 0,01 & 55 & 0,05 & 10 & 0,01 & $-67,7$ \\
\hline Cundinamarca & 40 & 0,05 & 4 & 0,01 & 97 & 0,08 & 8 & 0,01 & 58,1 \\
\hline Tolima & 55 & 0,07 & 9 & 0,01 & 67 & 0,06 & 11 & 0,01 & 17,9 \\
\hline Santander & 53 & 0,07 & 16 & 0,02 & 61 & 0,05 & 8 & 0,01 & 0,0 \\
\hline Without information & 42 & 0,05 & 16 & 0,02 & 50 & 0,04 & 13 & 0,01 & 7,9 \\
\hline Cesar & 24 & 0,03 & 3 & 0 & 65 & 0,06 & 2 & 0 & 59,7 \\
\hline Casanare & 33 & 0,04 & 10 & 0,01 & 36 & 0,03 & 7 & 0,01 & 0,0 \\
\hline Huila & 22 & 0,03 & 4 & 0,01 & 22 & 0,02 & 3 & 0 & $-4,0$ \\
\hline Arauca & 30 & 0,04 & 3 & 0 & 13 & 0,01 & & 0 & $-153,8$ \\
\hline Atlántico & 23 & 0,03 & 6 & 0,01 & 10 & 0,01 & 1 & 0 & $-163,6$ \\
\hline Santa Marta & & 0 & & 0 & 38 & 0,03 & 2 & 0 & 100,0 \\
\hline Cartagena & & 0 & & 0 & 16 & 0,01 & 12 & 0,01 & 100,0 \\
\hline Bogotá & 16 & 0,02 & & 0 & 5 & 0 & 5 & 0 & $-60,0$ \\
\hline Barranquilla & & 0 & & 0 & 15 & 0,01 & 4 & 0 & 100,0 \\
\hline San Andrés & & 0 & 1 & 0 & 5 & 0 & 3 & 0 & 87,5 \\
\hline Total & 56.780 & 72,04 & 21.340 & 21.340 & 82.856 & 70,75 & 32.777 & 27,99 & \\
\hline
\end{tabular}




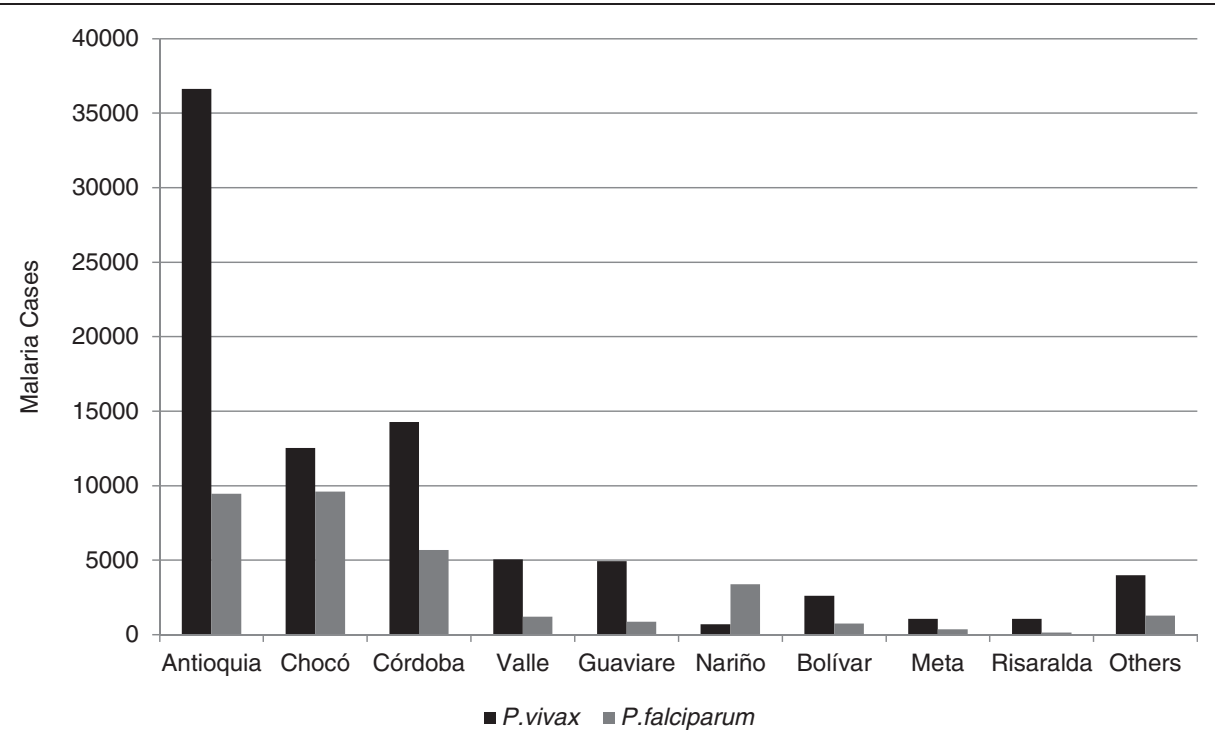

Figure 3 Distribution of malaria by department, Colombia, 2010.

consulted within the first 48 hours after symptom onset. These deaths occurred in non-pregnant women (15) and men (eight) from Chocó (seven); half in Antioquia, Córdoba, Valle del Cauca and Risaralda departments which reported three deaths each. In about half of the fatal cases $(47.8 \%)$, self-medication was associated to the case reported.

\section{Discussion}

Although a decreasing trend in the number of annual malaria cases has been reported in Colombia since 2001, transmission peaks were observed in 2007 and 2010, the latter representing a $32.6 \%$ increase from the previous year
(2009). Such an increase corresponds to a seasonal epidemic transmission outbreak that coincided with the paraquinquenal malaria transmission peak period described in areas of low transmission [14]. This outbreak was more evident in the traditionally highest transmission regions, i.e., departments of Antioquia, Córdoba, Chocó, Valle, Guaviare, Nariño, and Bolivar. Although this cyclical behaviour is considered to be due mainly to climatic changes induced by the El Niño phenomenon, several other determinants may have contributed to the malaria transmission increase. Social factors such as increased population migration through high malaria transmission areas occurred during the same period due to illegal agriculture

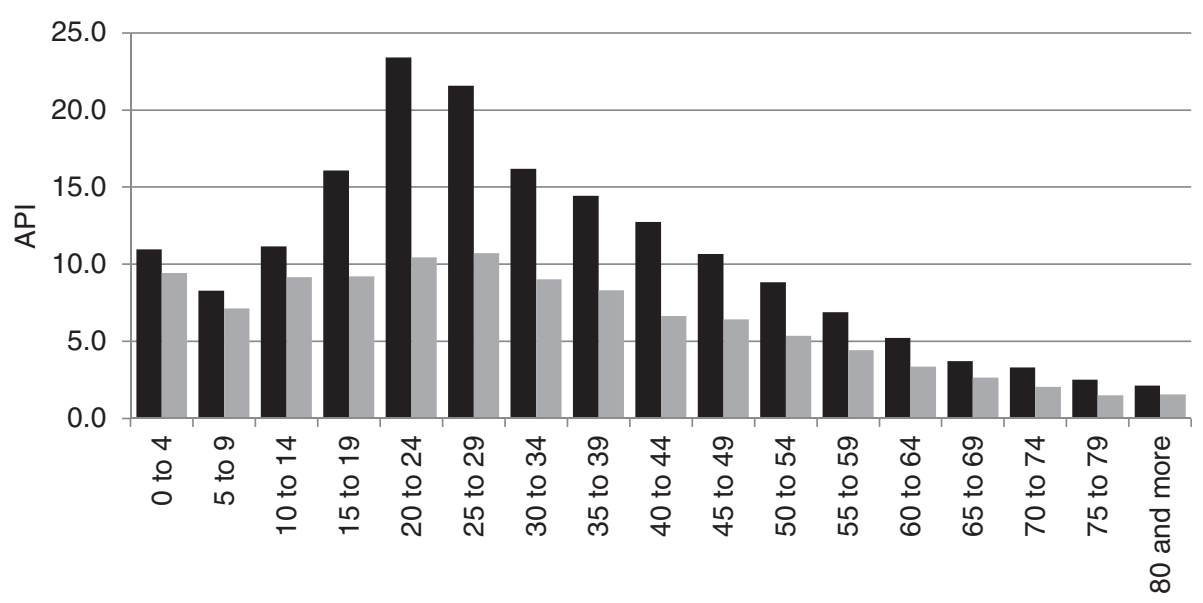

Age Groups

- Men Women

Figure 4 Annual parasite index by gender and age, Colombia, 2010. 
Table 3 Time between onset of symptoms and time of consultation

\begin{tabular}{|c|c|c|c|c|c|c|c|c|c|c|}
\hline \multirow[t]{2}{*}{ Time } & \multicolumn{2}{|c|}{ P. vivax } & \multicolumn{2}{|c|}{ P. falciparum } & \multicolumn{2}{|c|}{ Mixed infections } & \multicolumn{2}{|c|}{ P. malariae } & \multicolumn{2}{|c|}{ Total } \\
\hline & $\mathbf{n}$ & $\%$ & $\mathbf{n}$ & $\%$ & $\mathbf{n}$ & $\%$ & $\mathbf{n}$ & $\%$ & $\mathrm{~N}$ & $\%$ \\
\hline 24 hours & 29.276 & 35,3 & 11.904 & 36,3 & 388 & 27,2 & 19 & 40,4 & 41.587 & 35,5 \\
\hline 48 hours & 15.612 & 18,8 & 6.043 & 18,4 & 278 & 19,5 & 5 & 10,6 & 21.938 & 18,7 \\
\hline 72 hours & 13.213 & 15,9 & 4.995 & 15,2 & 226 & 15,8 & 8 & 17,0 & 18.442 & 15,7 \\
\hline More than 96 hours & 24.753 & 29,9 & 9.828 & 30,0 & 536 & 37,5 & 15 & 31,9 & 35.132 & 30,0 \\
\hline Don't know & 2 & 0,0 & 7 & 0,0 & & 0,0 & & 0,0 & 9 & 0,0 \\
\hline Total & 82.856 & 100,0 & 32.777 & 100,0 & 1.428 & 100,0 & 47 & 100,0 & 117.108 & 100, \\
\hline
\end{tabular}

Colombia, 2010.

Source: SIVIGILA.

and mining, which both resulted in environmental degradation. In addition, significant community displacement was forced by the growing presence of both legal military corps and insurgent troops through areas of high malaria transmission.

Because of its geographical location, most regions of Colombia present interposed rainy and dry seasons during the entire year, leading to relatively constant malaria transmission without the classical epidemic peaks observed in other latitudes [15,16]. It is not clear why most cases (66.3\%) presented during the first half of the year during which the most endemic regions presented a dry behaviour associated with El Niño, followed during the second half by La Niña (rainy season). This could have been due in part to inadequate administrative infrastructure at NMCP, as well as to the political instability that was most evident in endemic regions. First, it appears like there were deficiencies in providing timely diagnosis and treatment due to administrative issues that led to insufficient recruitment and hiring of microscopists in rural areas. Second, the staffing constraints in NMCP appeared to be further complicated by limitations placed on routine performance of prevention and control activities due to security concerns arising from the intensification of social conflict in the most endemic areas [7]. Indeed, the most endemic departments, Antioquia, Córdoba, Chocó, Valle, Guaviare, Nariño and Bolivar, presented IPA above the national mean, 10.5 cases/1,000 inhabitants; and all are known to be affected by the conditions described above. In these regions, mining and illegal agriculture usually leads to environment damage, and establishment of temporary settlements with poor households. Third, although records indicate that two-thirds of cases were reported in individuals who in theory had social security (EPS, IPS), in reality, under the social conditions described, access to health care is not adequate when these communities are left in the hands of a debilitated NMCP.

Antioquia and Cordoba corresponded to the highest risk according to the API with 57.0 and $64.5 \%$, respectively, and together with Chocó, accounted for the greatest percentage $(82.5 \%)$ of cases in children $<15$ years of age, which correlates with high malaria transmission in these areas [17]. The parasite species distribution did not present any change in this epidemic year as compared with the proportion over the last decade where most cases ( 74\%) were produced by $P$. vivax. This higher prevalence of $P$. vivax was even greater in the group $\leq 15$ years old (1.25 times) than in older individuals. As expected, the most endemic departments presented a greater number of cases in children and in pregnant women.

It is interesting to note that in spite of the epidemic behaviour during this period, and that most cases (63.0\%) were from rural areas where there is inadequate access to diagnosis and treatment, over half of the malaria cases consulted early after symptoms onset (first 48 hours). This early consultation may explain the low frequency of complicated $(0.5 \%)$ and lethal $(0.02 \%)$ cases. In addition, the high prevalence of acute but clinically benign cases may also be due to the fact that most cases (70.8\%) were caused by $P$. vivax with only $1.2 \%$ of reported cases

Table 4 Complicated malaria cases by parasite species

\begin{tabular}{|c|c|c|c|c|c|c|}
\hline & \multicolumn{6}{|l|}{ Parasite species } \\
\hline & P. vivax $(\mathrm{n}=293)$ & $P$. falciparum $(n=282)$ & mixed $(n=32)$ & P. malariae $(\mathrm{n}=6)$ & unreported $(n=10)$ & Total $(n=623)$ \\
\hline Cerebral & $44(7,1 \%)$ & $59(9,5 \%)$ & $6(1,0 \%)$ & $1(0,2 \%)$ & 0 & $110(17,7 \%)$ \\
\hline Renal & $66(10,6 \%)$ & $88(14,1 \%)$ & $10(1,6 \%)$ & $2(0,3 \%)$ & $1(0,2 \%)$ & $167(26,8 \%)$ \\
\hline Liver & $130(20,9 \%)$ & $99(15,9 \%)$ & $14(2,2 \%)$ & $1(0,2 \%)$ & 0 & $244(39,2 \%)$ \\
\hline Pulmonary & $34(5,5 \%)$ & $31(5,0 \%)$ & $1(0,2 \%)$ & $2(0,3 \%)$ & 0 & $68(10,9 \%)$ \\
\hline unreported & $19(3,0 \%)$ & $5(0,8 \%)$ & $1(0,2 \%)$ & 0 & $9(1,4 \%)$ & $34(5,5 \%)$ \\
\hline
\end{tabular}

Source: SIVIGILA. 
corresponding to mixed infections. The low frequency of complications and mortality may also be due to the population displacements that occurred within endemic regions and that probably involved communities that had already been significantly exposed to malaria.

It is of concern that about one-third of the cases (37\%) were reported as originating in urban and peri-urban settings. It is extremely important to determine if there were actually $15 \%$ of urban cases or if these corresponded to inaccurately recorded cases. Despite the great risk of maintaining urban malaria transmission, little is known about the potential vector species in such localities. A total of 21 municipalities with well-defined urban areas were reported as having such cases. Even if the cases are occurring in less formally urbanized areas, increased attention must be devoted to elucidate the origin of these cases, as well as on intervening in such settings, which would not only decrease the risk of transmission, but would also prove to be more cost effective. Although, transmission may be occurring in urban areas recently colonized, where mosquito vectors are becoming adapted $[18,19]$, it might also be that patients report false addresses or case origin, just to avoid being associated to illegal activities. In any case, a high proportion of the urban population lives in extreme poverty, with limited access to health and education [20] and have higher risk of severe disease due to the lack of protective immunity.

Although most cases (64.6\%) occurred in men with higher API values converging in the group 20 to 29 years of age, one third (30.3\%) occurred in children under 15 years old. In contrast to holo-endemic and hyperendemic regions in Africa and Asia (PNG) where greater morbidity and mortality occur in children and infants, only a limited proportion of the cases presented in children $<5$ years of age. In this case, one-third of the cases occurred in children $<15$ years/age, which may indicate transmission in the household and school neighborhood. Fewer malaria cases were reported in women, although $\sim 26 \%$ of these occurred in women of reproductive age (ten to 54 years), $<1 \%$ of them were pregnant at the time of diagnosis. Previous studies conducted in areas of high risk for the disease had indicated a higher number of malaria cases during pregnancy in Colombia with prevalences between nine and 10.4\% [21,22]. The contrast of these figures to the ones reported here may be due to the fact that those studies were performed in areas of highest transmission, whereas here we have included surveillance data of the entire country. Indeed > $65 \%$ of the cases were reported from Antioquia (45.8\%); Córdoba (11.6\%); and Chocó (8.4\%).

Another possible explanation for these contrasting figures is an inaccurate or incomplete recording of the gestational status at the time of malaria diagnosis, where information on the pregnancy status of malarial women of child-bearing age might have not been properly recorded resulting in a reduction in the number of reported malaria cases in pregnant women. This has been observed in Brazil and other countries of the region, where the actual frequency of malaria and pregnancy is unknown [23]. Additionally, studies focused on malaria and pregnancy, have focused more attention to properly recording the study data. In a previous patient capture - recapture study conducted in Urabá, of estimated a that SIVIGILA presented underreporting of $80 \%$ of pregnant women with malaria [24]. This stresses the need of better training for staff performing data collection by implementing regular courses, strengthening awareness and reporting procedures.

Neither the malaria distribution by ethnic group nor the distribution by occupation appears to have changed from that reported in 2009. Almost 70\% of cases occurred in white and mestizo populations, followed by $\sim 23 \%$ reported in African descent groups. Likewise, students, miners, housewives, and children of both genders accounted for $\sim 60 \%$ of the cases. It is not surprising that only $623(\sim 0.5 \%)$ complicated malaria cases were reported since early diagnosis was a rule, this consequently explains the low rate of mortality. Although complicated cases were distributed in all age groups, lethal cases occurred in young patients ( $<29$ years) although not necessarily in children. It is not surprising that these complicated cases were equally distributed between the two parasite species as $P$. falciparum was less frequent but is more pathogenic than $P$. vivax. In contrast, $P$. vivax, which have been considered benign, has been recently reported to be responsible for severe and complicated cases as well as for significant mortality [25]. The incidence of clinical complications by $P$. vivax is unknown and the clinical profile of this species has been poorly studied and is probably not well recognized by physicians. Surprisingly, $>40 \%$ of the complicated cases were recorded as having consulted within the first 48 hours after symptom onset. Data analysed here correspond to malaria cases diagnosed by thick smear, however, as PCR malaria diagnose has been introduced, recent studies have started reporting that malaria by $P$. vivax could be as deadly as malaria by $P$. falciparum [26]. Although some hypotheses suggest that the chloroquine-primaquine combination, which has been the first-line of treatment for $P$. vivax for almost 50 years, may not be equally effective nowadays, there is no evidence for this decrease in effectiveness in Colombia. Similarly, other studies report wrong diagnosis of the species [27] which affects the clinical decision about the recommend treatment [28]. In fact, individuals experimentally infected in the context of vaccine clinical trials have responded to this combination, with parasite clearance between 24-48 hours after treatment initiation 
$[29,30]$. One could speculate that there was poor compliance with the official anti-malarial therapy, particularly in those fatal cases where self-medication was reported.

This paper presents constraints arising from taking information from a secondary source with possible notification mistakes, presence of ignored or uncompleted fields, and lack of consistency in some variables. There may also be errors in the digitization of information that could lead to underestimating the real number of malaria cases [31]. In addition, there may be misclassification of cases given by errors in diagnosis and lack of adherence to case definitions used for surveillance. The lack of special units for analysis of complicated malaria or malaria deaths at the NMCP and the reluctance of the SSS to assume the responsibility of malaria diagnoses and treatment are currently limiting the quality of information. Currently, the Ministry of Health is articulating different information systems and ongoing studies are being complemented with information from other sources, such as from individual records services (known as RIPS = Registros Individuales de Prestación de Servicios de Salud), as well as from mortality records and from entomological surveillance data. Quantitative and descriptive studies could help to better establish the real magnitude of the events and analytical studies could determine other factors associated with the presence of the disease.

During the last two years (2011-2012), there has been a significant malaria decrease ( 61,000 cases/year), despite the fact that major determinants, such as population migration, illegal agriculture and mining appears to be growing as well as the presence of both legal military corps and insurgent troops. This indicates the great efforts of the country to decrease malaria transmission, during the last couple of years a more timely diagnosis and treatment as well as prevention and control activities are being deployed jointly between the NMCP and the GF project, which appear to be producing a beneficial impact.

These local factors may explain why whereas countries like those of Central America or Peru and Ecuador are substantially reducing malaria transmission, Colombia remains with significantly greater transmission. However the evolution during the last decade has brought transmission from $\sim 200,000$ cases/year [32], to $\sim 61,000$ cases in 2012 (SIVIGILA 2013), and currently, greater efforts are being invested to maintain the decreasing trend, although permanent monitoring to avoid epidemic outbreaks is still required i.e. by prioritizing critical control activities such as effective vector management and educational activities as well as greater efforts to overcome administrative hurdles that limit a more robust diagnosis and treatment system. In the context of the GF project, the COMBI strategy (social mobilization for behaviour change) is successfully leading to community participation in prevention and control activities that therefore become more efficient and cost-effective [20,33-35]. Moreover, in the framework of national and international research projects such as Malaria Research Network sponsored by the Colombian government, and (International Centers of Excellence for Malaria Research-ICEMR) sponsored by the US National Institutes of Health $(\mathrm{NIH})$ the NMCP has been involved in translation malaria research projects, including studies leading to define the etiology and potential co-morbidities of complicated and lethal $P$. vivax cases as well as the real intensity of urban malaria transmission. These new initiatives are likely to generate new strategies to force the malaria incidence downwards in the following years.

\section{Competing interests}

The authors declare that they have no competing interests.

\section{Authors' contributions}

JP and PC conceived and designed the study. SH, AV and PC wrote the manuscript. All authors read and approved the final manuscript.

\section{Acknowledgements}

We thank the support of the Sub-dirección de Vigilancia y Control en Salud Pública-INS and to SIVIGILA for making the data available. This work was supported by the Ministry of Health of Colombia, as well as by Colciencias (research grant 360-2011) and the NIAID/ICEMR (research grant U19AI089702).

\section{Author details}

${ }^{1}$ National Institute of Health of Colombia, Bogotá, Colombia. ${ }^{2}$ National University of Colombia, Bogotá, Colombia. ${ }^{3}$ Ministry of Health and Social Protection of Colombia, Bogotá, Colombia. ${ }^{4}$ Caucaseco Scientific Research Center, Cali, Colombia. ${ }^{5}$ Latin American Center for Malaria Research, Cali, Colombia.

Received: 20 July 2013 Accepted: 11 September 2013

Published: 17 September 2013

\section{References}

1. Centers for Disease Control and Prevention: Malaria surveillance-United States, 2009. MMWR 2011, 60:1-15.

2. Rojo Marcos G, Cuadros González J, Gete García L, Gómez Herruz P, López Rubio M, Esteban Gutiérrez G: Infección por Plasmodium ovale: descripción de 16 casos y revisión del tema. Enferm Infecc Microbio/ Clin 2011, 29:204-208.

3. Martínez-Salazar E, Tobón-Castaño A, Blair S: Malaria en humanos por infección natural con Plasmodium knowlesi. Biomedica 2012, 32:121-130.

4. World Health Organization: Global health observatory data repository. 2011. http://apps.who.int/gho/data/view.main who int/ghodata 2011.

5. WHO: World malaria report. Geneva: World Health Organization; 2010. Availabe http://www.who.int/malaria/world_malaria_report_2010/en/

6. Instituto Nacional de Salud Pública: Manual para la vigilancia y el control del paludismo en Mesoamérica. Méjico: Subdirección de Comunicación Científica y Publicaciones del INSP; 2008

7. Padilla J, Peña S: Situación epidemiológica de la malaria en Colombia. Inf Quin Epidemiol Nac 2002, 7:333-346.

8. Instituto Nacional de Salud: Protocolo de vigilancia en salud pública de la malaria. http://www.ins.gov.co/temas-de-interes/Documentacin\%20Malaria/ 01\%20Protocolo\%20Malaria.pdf.

9. Guerra C, Snow R, Hay S: Defining the global spatial limits of malaria transmission in 2005. Adv Parasitol 2006, 62:157-179.

10. Malaria control and community systems strengthening consultation. http://www. rollbackmalaria.org/toolbox/tool_CommunitySystemsStrengthening.html.

11. Ospina O, Cortés L, Cucunubá Z, Mendoza N, Chaparro P: Caracterización de la red nacional de diagnóstico de malaria, Colombia, 2006-2010. Biomedica 2012, 32:46-57. 
12. Padilla J, Piñeros J: Situación de la malaria en el Pacífico nariñense durante el año 2001. Informe preliminar Informe Quincenal Epidemiológico Nacional 2001, 6:269-273.

13. Instituto Nacional de Salud: Depuración de las bases de datos: algoritmos y diagnóstico inicial. Bogotá: Grupo Sivigila: Pública SdVyCeS; 2010.

14. Gabaldón A: Malaria incidence in the west Indies and South America. In Malariology. M B Philadelphia: WB Saunders Co; 1949:764-787.

15. Pabón JD, Nicholls RS: El cambio climático y la salud humana. Biomedica 2005, 25:5-8.

16. Poveda G, Rojas W: Evidencias de la asociación entre brotes epidémicos de malaria en Colombia y el fenómeno El Niño-Oscilación del Sur. Revista de la Academia Colombiana de Ciencias 1997, 21:421-429.

17. Brown W: Risk factors of malaria incidence in Ghana: a case study of Obuasi Government Hospital. Am J Gov Polit 2013, 3:50-54.

18. Martens $P$, Hall L: Malaria on the move: human population movement and malaria transmission. Emerg Infect Dis 2000, 6:103.

19. Sawyer D: Economic and social consequences of malaria in new colonization projects in Brazil. Soc Sci Med 1993, 37:1131-1136.

20. Robert V, Macintyre K, Keating J, Trape JF, Duchemin JB, Warren M, Beier JC: Malaria transmission in urban sub-Saharan Africa. Am J Trop Med Hyg 2003, 68:169-176.

21. Franco S, Blair S, Aristizábal M, Gómez J, Cañas L, Posada A: Malaria congénita. Medellín: Informe final Facultad de Medicina y Centro de Investigaciones Médicas, Universidad de Antioquia; 1985.

22. Carmona-Fonseca J, Maestre AB: Incidence of gestational, congenital and placental malaria in Urabá (Antioquia, Colombia), 2005-2007. Rev Colomb Obstet Ginecol 2009, 60:19-33.

23. Chagas ECDS, Nascimento CTD, Santana Filho FSD, Bôtto-Menezes CH, Martinez-Espinosa FE: Impact of malaria during pregnancy in the Amazon region. Rev Panam Salud Publica 2009, 26:203-208.

24. Arismendi MJ: Magnitud de la malaria gestacional en el Urabá Antioqueño 2000-2005. PhD thesis. Universidad de Antioquia. Facultad Nacional de Salud Pública Héctor Abad Gómez; 2009.

25. Tan LK, Yacoub S, Scott S, Bhagani S, Jacobs M: Acute lung injury and other serious complications of Plasmodium vivax malaria. Lancet Infect Dis 2008, 8:449-454.

26. Nurleila S, Syafruddin D, Elyazar IR, Baird JK: Serious and fatal illness associated with falciparum and vivax malaria among patients admitted to hospital at West Sumba in eastern Indonesia. Am J Trop Med Hyg 2012, 87:41.

27. Barcus MJ, Basri H, Picarima H, Manyakori C, Elyazar I, Bangs MJ, Maguire JD, Baird JK: Demographic risk factors for severe and fatal vivax and falciparum malaria among hospital admissions in northeastern Indonesian Papua. Am J Trop Med Hyg 2007, 77:984-991.

28. Mendis K, Sina BJ, Marchesini P, Carter R: The neglected burden of Plasmodium vivax malaria. Am J Trop Med Hyg 2001, 64:97-106.

29. Herrera S, Solarte $Y$, Jordan-Villegas A, Echavarria JF, Rocha L, Palacios R, Ramirez O, Velez JD, Epstein JE, Richie TL, Arevalo-Herrera M: Consistent safety and infectivity in sporozoite challenge model of Plasmodium vivax in malaria-naive human volunteers. Am J Trop Med Hyg 2011, 84:4-11.

30. Herrera S, Fernandez O, Manzano MR, Murrain B, Vergara J, Blanco P, Palacios R, Velez JD, Epstein JE, Chen-Mok M, Reed ZH, Arévalo-Herrera M: Successful sporozoite challenge model in human volunteers with Plasmodium vivax strain derived from human donors. Am J Trop Med Hyg 2009, 81:740-746.

31. Erhart A, Thang N, Xa N, Thieu N, Hung L, Hung N, Nam N, Toi L, Tung N, Bien $T$ : Accuracy of the health information system on malaria surveillance in Vietnam. Trans R Soc Trop Med Hyg 2007, 101:216-225.

32. Rodríguez JCP, Uribe GÁ, Araújo RM, Narváez PC, Valencia SH: Epidemiology and control of malaria in Colombia. Mem Inst Oswaldo Cruz 2011, 106:114-122.
33. Newman RD, Parise ME, Barber AM, Steketee RW: Malaria-related deaths among U.S. travelers, 1963-2001. Ann Intern Med 2004, 141:547-555.

34. Saeed IE, Ahmed ES: Determinants of malaria mortality among displaced people in Khartoum state, Sudan. East Mediterr Health J 2003, 9:593-599.

35. Dürrheim DN, Frieremans S, Kruger P, Mabuza A, De Bruyn JC: Confidential inquiry into malaria deaths. Bull World Health Organ 1999, 77:263-266.

doi:10.1186/1475-2875-12-330

Cite this article as: Chaparro et al:: Characterization of a malaria outbreak in Colombia in 2010. Malaria Journal 2013 12:330.

\section{Submit your next manuscript to BioMed Central and take full advantage of:}

- Convenient online submission

- Thorough peer review

- No space constraints or color figure charges

- Immediate publication on acceptance

- Inclusion in PubMed, CAS, Scopus and Google Scholar

- Research which is freely available for redistribution

Submit your manuscript at www.biomedcentral.com/submit
C Biomed Central 